\title{
The decline in job-to-job flows
}

\section{An aging workforce and declining entrepreneurship explain the decline in job-to-job flows only partially}

Keywords: job-to-job, employer-to-employer, employment, hiring, firing, separations, layoffs, quits

\section{ELEVATOR PITCH}

As part of a more general process of employment reallocation from less to more productive employers, jobto-job flows tend to be beneficial for productivity and for workers. Thus, when this rate slows, it is important to understand why. In the US, for example, the job-to-job flow rate is now at an all-time low. While job-to-job flows are a means of boosting wages and productivity, a decline could indicate improvements for workers if it means that they are now better matched to their jobs. Furthermore, when job-to-job flows are lower, firms and workers incur fewer costs related to job transitions, such as job search and hiring costs.

\section{KEY FINDINGS}

\section{Pros}

๑ Job-to-job flow rates are generally the result of voluntary quits for better jobs.

๑ Changing employers usually involves a wage increase, especially for young workers.

๑ Job-to-job flows are part of efficiency-enhancing resource reallocation: productive employers tend to expand, and less productive ones to contract.

๑ Workers are generally in their jobs longer after switching employers.

( Changes in labor market composition, such as the aging workforce, rising educational attainment, and declining entrepreneurship, explain some of the decline in the job-to-job flow rate.

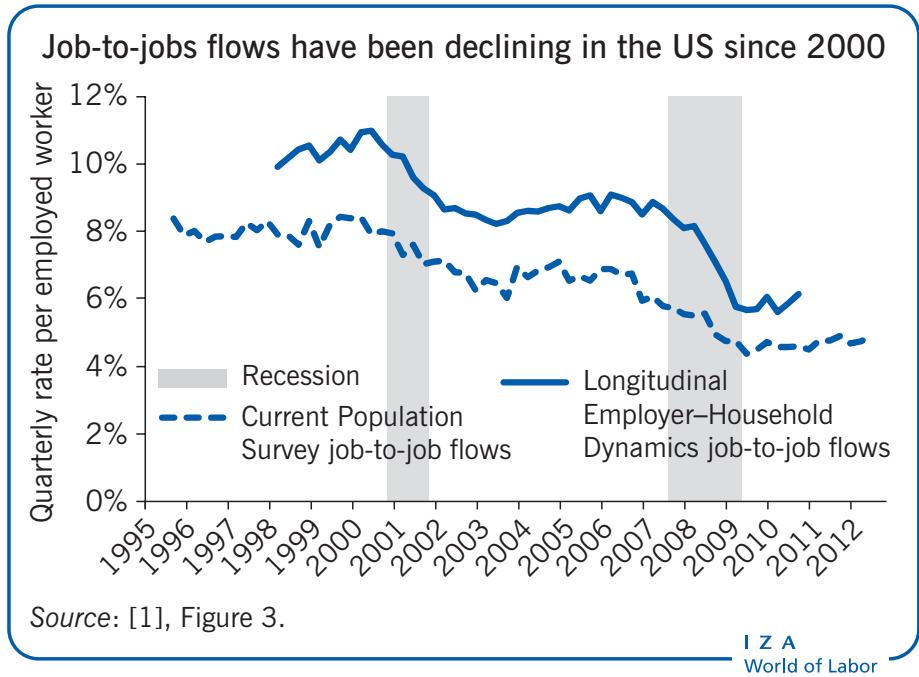

\section{Cons}

- Job transitions are costly: workers have to look for work, and employers must post vacancies and interview new applicants.

- Worker-accumulated job-specific skills may not be put to productive use after a worker changes jobs.

- Some direct job-to-job flows are involuntary, and these often involve worse matches and pay cuts.

- The main causes of the decline in the job-to-job flow rate are unknown.

- Little information is available on job-to-job flows in countries other than the US.

\section{AUTHOR'S MAIN MESSAGE}

Job-to-job flows generally reflect workers' moves to jobs that pay more and last longer. But job-to-job flows also involve job search and training costs, and the loss of valuable employer-specific experience. Thus, any single job-to-job transition may be good or bad for a particular employee or employer. New US data indicate that job-to-job flows have slowed dramatically since 2000. While the aging of the workforce and the decline in entrepreneurship explain some of the decline, a large share is unexplained. A slowdown would be worrisome if it means that there is not a steady stream of new jobs that are more productive than existing ones. 


\section{MOTIVATION}

Workers often leave one employer and take a job at another. As part of a more general process of employment reallocation from less productive to more productive employers, such job-to-job flows tend to be beneficial for productivity and for workers, for at least two reasons. First, wages tend to increase after a job-to-job transition. For most workers, these changes are associated with estimated earnings increases of 3.5-9\%. For young workers under 30 years old-who are most likely to undergo such a change in employersthe median increase is more than 10\% [2]. Second, employees tend to stay longer at the subsequent job than at the previous job.

For both of these reasons, the common view is that a job's quality or productivity is greater after a job-to-job flow than before. However, not all job-to-job transitions are wholly voluntary movements, even if many of these transitions are the result of voluntary quits. Thus, the subsequent job may be a worse match between worker and job than the previous one and may involve pay cuts.

Using the US as an example, this paper provides an overview of job-to-job flows, notes their decline in the past 30 years, and examines some likely reasons for the decline. While good data are available for job-to-job flows in the US, such data are not available for other countries.

\section{DISCUSSION OF PROS AND CONS}

\section{Decline in job-to-job flows since 2000}

The rate of job-to-job flows has declined in the US since 2000 [2]. This decline is related to a broader decline in employment dynamics around the same time: the rate of hires and separations declined, as did the rates at which jobs were created (through business entry and expansion) and destroyed (through business contraction and exit) [1]. Additionally, the decline in job-to-job flows may explain much of the decline in residential migration between states that occurred at roughly the same time [3].

\section{What are job-to-job flows?}

Job-to-job flows (sometimes called employer-to-employer flows) occur when workers switch employers with little to no gap between jobs. Job-to-job flows are distinct from hires from and separations to nonemployment (either unemployment or nonparticipation in the labor force). In the simplest case, a job-to-job flow occurs when a worker quits one company and is immediately hired by another.

Most measures of job-to-job flows permit some short spells of nonemployment between jobs at the previous and subsequent employer. Depending on the amount of detail in the data source, common permitted gaps are one week, up to one month, and up to three months.

Since workers can work for multiple employers simultaneously, there can be some overlap. US data sources that measure job-to-job flows keep track of a person's single dominant employer and identify transitions with respect to that employer. 


\section{Why do workers switch jobs?}

Workers switch jobs for a variety of reasons, but the typical job-to-job flow involves a worker's voluntary separation after receiving a job offer from another employer. Usually, such moves are associated with an increase in earnings, and since the worker has higher earnings, it is assumed that the employee-job match is more productive. The match may be more productive because the new employer is more productive or because the worker is a better fit for the new job than for the previous one. The benefits of job switching are greater economic output and higher wages. Because most job-to-job flows are voluntary movements, many such flows are unambiguously positive for workers. Furthermore, the fact that workers switch jobs means that firms have a larger pool of potential employees from which to recruit workers: they are not limited to people without jobs but may recruit workers at other firms.

However, job switches involve costs as well as benefits. For employers, it is costly to spend time recruiting workers-posting and advertising vacancies, reviewing resumes, and interviewing potential employees. For workers, it is also costly to seek out new employers; workers have to prepare a resume, review job listings, and may even need to relocate. And even after these initial costs have been incurred, workers need time to become acclimated to their new job, and employers may need to provide some training for the worker, so productivity may be lower at the start of a new job.

Furthermore, for workers who leave a job, any employer-specific experience they may have gained is lost to the workers and the employer. The most experienced workers who leave their jobs tend to experience substantial earnings losses [2]. Well-matched workers tend to stay in their current job: a conventional explanation for why older workers tend to switch jobs less often than younger workers is that they have had more opportunities to find a job that is the best fit for them.

\section{How are job-to-job flows measured?}

An increasing number of detailed data sources permit researchers to measure job-tojob flows in the US. Starting in 1976, the US Current Population Survey began asking respondents to its March Annual Social and Economic Supplement how many jobs they held in the last year. Several studies use time series data on this measure. One study uses the share of the workforce with two or more jobs as a measure of job stability [4]. Another study uses additional data from the survey to add job-to-job transitions that this measure misses and to highlight subsets of the data for job-to-job flows with an intervening nonemployment spell [5]. Yet another study uses the microdata available following the 1994 redesign of the survey that asks respondents whether they are still working for the same employer as they had been during the previous monthly interview [6]. The study uses the frequency with which the respondents say no, and the presence of a new job, to create a job-to-job flows time series. Responding about a new employer is a very strong indication of a job-to-job flow.

More recently, the US Census Bureau's Longitudinal Employer-Household Dynamics program has developed a method for identifying job-to-job flows using administrative records. The US states submit information to the Census Bureau on total quarterly earnings for all unemployment insurance taxable earnings. These data are used to measure the frequency with which a worker's employer changes. The construction of these data 


\section{US data sources for job-to-job flow rates}

Several data sources can be used to measure job-to-job flows in the US economy. Rates are usually calculated by dividing the measure of transitions by the employed population.

- The March Current Population Survey asks workers for the total number of employers that they have worked for in the last year. A refinement was added to the survey in 1994. Each month, for three months, respondents are prompted with the name of the employer they identified previously and are asked whether they still work there.

- Administrative records permit measurement based on employee records showing that they were receiving taxable earnings from one employer and then from another without any intervening period with no taxable earnings.

- $\quad$ The US Census Bureau recently produced a public-use data product derived from the Longitudinal Employer-Household Dynamics data, which combines data from state and federal sources to create a longitudinal linked employer-employee data set. This data set tabulates different types of employment transitions:

- Within-quarter job-to-job flows, when the previous and subsequent jobs have reported earnings.

- Adjacent-quarter job-to-job flows, when the previous job ends in the quarter before the subsequent job begins.

- Flows into and from nonemployment, for quarters in which a worker has no reported earnings.

- Other longitudinal or retrospective surveys, such as the Survey of Income and Program Participation, ask employees about employer switching. Job-to-job flow rates calculated from such data sources generally do not have a very long time series.

- $\quad$ The US Bureau of Labor Statistics produces monthly statistics from its Job Openings and Labor Turnover Survey, which asks employers about their employee separations and to distinguish between separations that occurred because the employee quit and those that occurred because the employee was laid off.

took several years (see [2] and [7]). In the recently released public-use data product, jobto-job flows are indicated by a change in the employer that is the dominant source of earnings. Special attention is given to cases where a change in the dominant employer was contemporaneous with a separation from the previous dominant employer and a hire at the new dominant employer.

Job-to-job flows track the business cycle (are procyclical) and are driven by job quits. When economic times are good, there are more opportunities for workers to profitably switch employers. The matching cyclicality of job-to-job flows and job quits is illustrated in Figure 1, which plots job-to-job flow rates (separations), the rate of transitions from employment to a full-quarter of nonemployment (administrative records do not indicate whether a worker is unemployed or out of the labor force), layoff rates, and quit rates. The job-to-job flow rate and the quit rate move together, and the correlation between them is very strong (0.98). Clearly, the source or sources of variation in these series are similar. In addition, the rate at which workers move into nonemployment tracks the layoff rate, although the correlation is not nearly as strong (0.61). 
Figure 1. Job-to-job flow rates and quit rates for 2001-2011 closely track each other in the US - as do transitions into unemployment and layoff rates

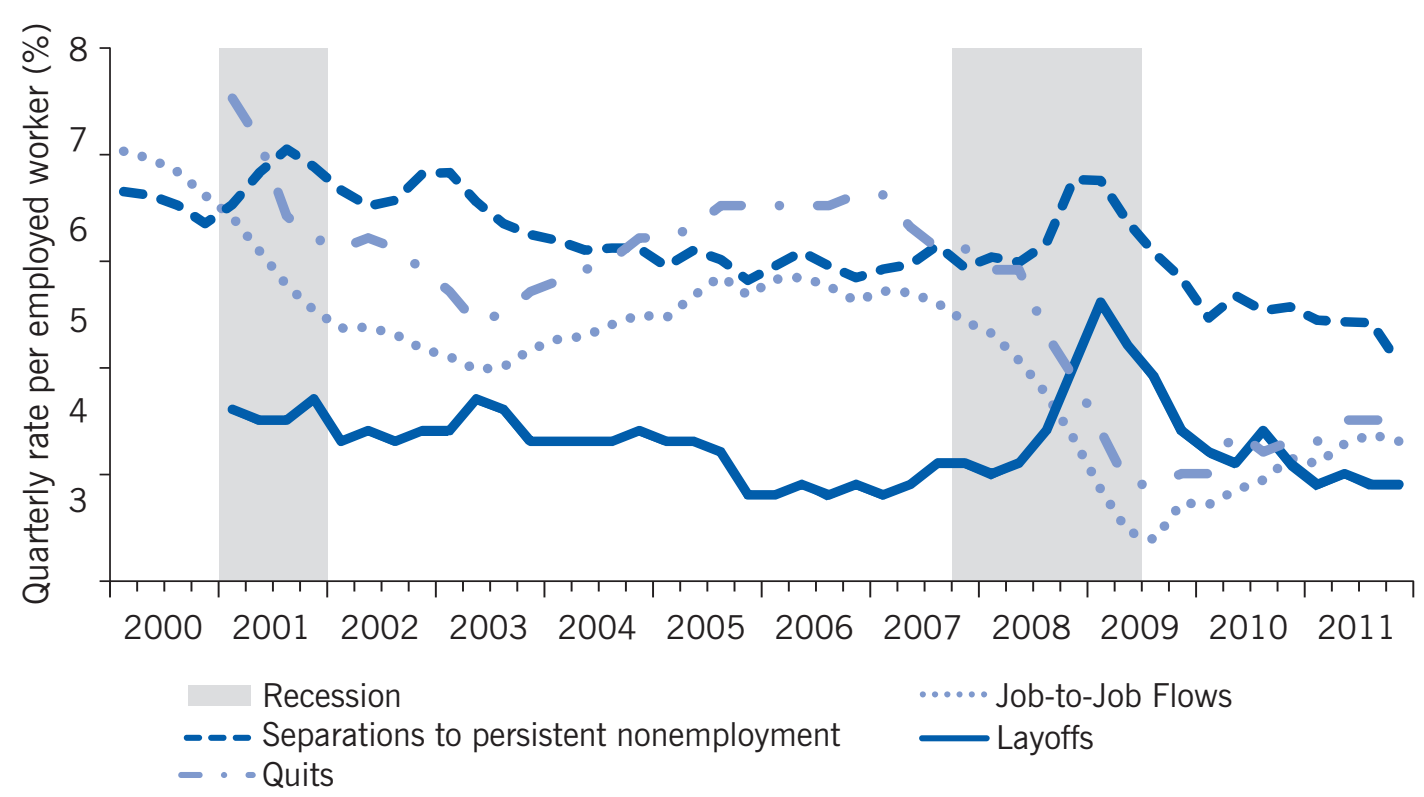

Note: Job-to-job flows and separations to persistent nonemployment (transitions from employment to a full quarter of nonemployment) are from the Longitudinal Employer-Household Dynamics program. Layoff and quit rate data are from the Job Openings and Labor Turnover Survey.

Source: Hyatt, H., E. McEntarfer, K. McKinney, S. Tibbets, and D. Walton. "Job-to-job (J2J) flows: New labor market statistics from linked employer-employee data." In: JSM Proceedings, Business and Economic Statistics Section. Alexandria, VA: American Statistical Association, 2014; pp. 98-110; Figure 4 [7].

\section{The trend from 1976 to 2014}

The job-to-job flow rate after the recent 2008-2009 recession is unprecedentedly low. One analysis notes that the job-to-job flow rate, along with other measures of employment dynamics, has followed a "stair-step" pattern since the late 1990s, with declines during recessions [1]. The US labor market exhibited a dramatic decline in the job-to-job flow rate around the time of the 2001 recession and had not fully recovered to its previous level when the 2008-2009 recession occurred and plunged the job-to-job flow rate to its lowest level in almost four decades. Recovery since then has been sluggish (see the illustration on p. 1). In both the Current Population Survey data and the Longitudinal Employer-Household Dynamics data, the job-to-job flow rate shrank to about half its level between 2000 and 2012.

The monthly Current Population Survey data and the quarterly Longitudinal EmployerHousehold Dynamics data confirm that the job-to-job flow rate is at a series low since the late 1990s. Data from the March Current Population Survey indicate that the US job change rate likely reached a 30-year low in the wake of the 2008-2009 recession.

Figure 2 shows an even longer historical series on employer change back to 1975, showing the share of the workforce that held two or more jobs in the year before the survey. One study considers this measure to be an indicator of job stability [4]. Another study argues that this measure identifies most of the job-to-job transitions in the Current Population Survey and also some transitions with intervening spells of nonemployment [5]. Having multiple employers in the last year is a reasonable proxy for job-to-job flows: 
Figure 2. The share of the workforce with two or more jobs in the past year, a proxy for (job-to-job flows, has fallen to its lowest level since 1976

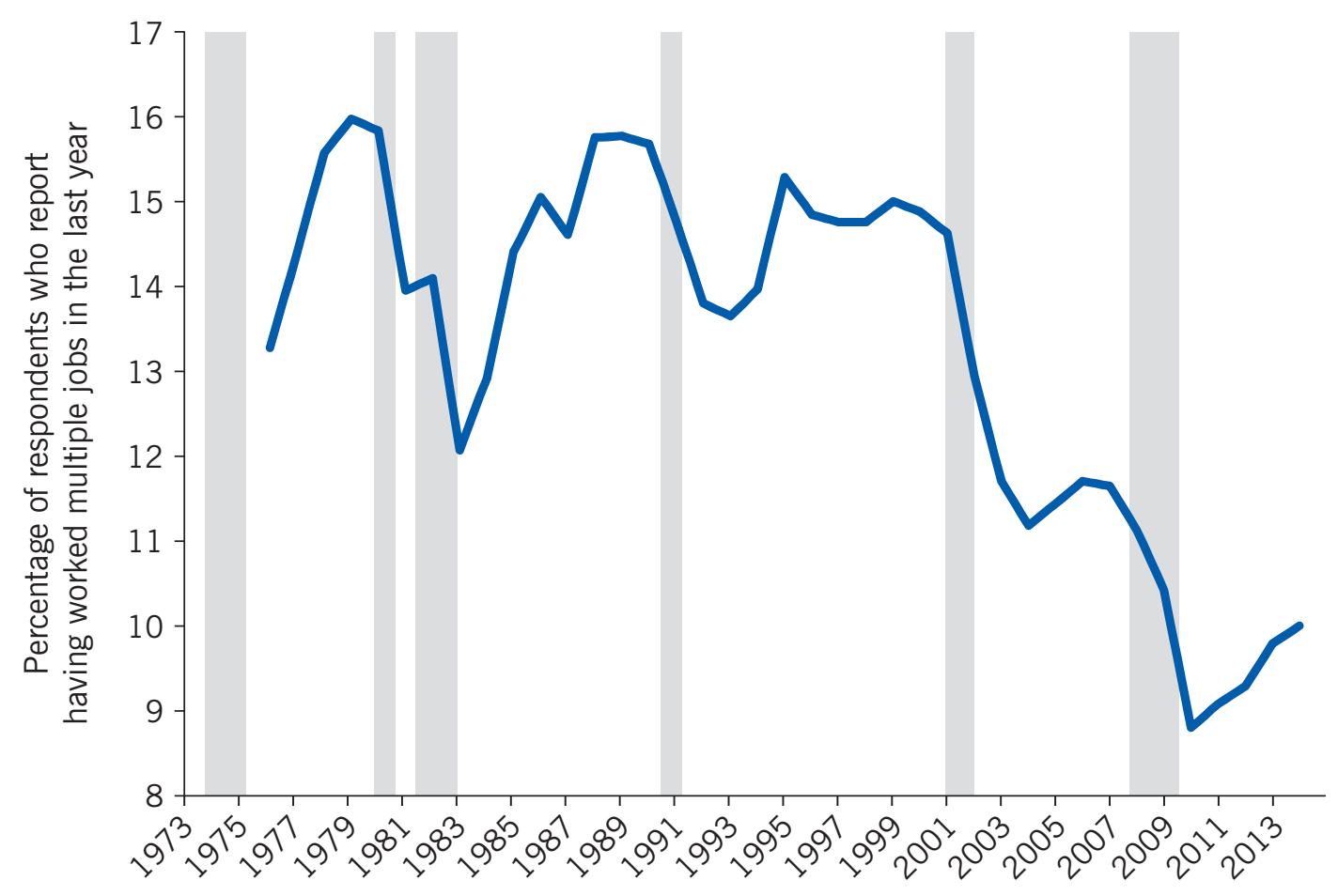

Note: Shaded areas indicate recessions

Source: Calculations based on data from the Current Population Survey. Online at: http://www.census.gov/cps/

the correlation between this measure and the more direct measure of job-to-job flows from the Longitudinal Employer-Household Dynamics data is strong (around 0.9).

The job-to-job transition rate inferred from the rate at which Current Population Survey respondents report working for multiple employers in the past year follows the business cycle and was generally around 15-16\% during the 1980s and 1990s. A low point was reached just after the 1982 recession, when the transition rate was only 12\%. In 1999, the rate was close to $15 \%$, but after the 2001 recession it reached a low of around $11 \%$ in 2004 before rising to nearly $12 \%$ in 2006 , when a new decline began. The job-to-job transition rate crashed to a series low of around $9 \%$ in 2010 and then began a slight recovery, reaching 10\% in 2014.

\section{Why has the job-to-job flow rate declined?}

There are many possible reasons for the decline in the job-to-job flow rate (Figure 3). One study that ran a series of tests on whether compositional changes in the workforce can explain the decline in the job-to-job flow rate finds that the aging of the US workforce may explain some of the decline in the aggregate job-to-job flow rate [1]. Since older workers tend to switch jobs less often than younger workers, the aging of the population explains 9\% of the decline in the job-to-job flow rate using data from the Current Population Survey and $21 \%$ using data from the Longitudinal Employer-Household Dynamics data. The decline in entrepreneurship in the US also explains some of the drop: the lower share of 
Figure 3. Potential reasons for the decline in the US job-to-job flow rate

Explanation Evaluation

\section{Confirmed by direct evidence}

Aging of the US workforce: Older workers change jobs less frequently.

Decline in US entrepreneurship: Start-ups have the highest rates of job turnover. Increase in the share of larger firms: Larger firms have lower job turnover.

Rising level of educational attainment:

Turnover is lower among more educated workers.

Plausible reasons, indirect evidence available Higher-skill jobs (higher training costs): If a job is more specialized, it may be more costly to train workers or to find very specialized workers to fill vacancies.

Globalization: The US has been a net importer since the 1990s, and employment may not change as much in response to shifts in demand for goods and services as before then.

Fewer job opportunities: If there are fewer profitable job opportunities, there will be less cause for workers to change jobs.

\section{Less plausible explanations}

Change in industry structure: Manufacturing and construction have declined. Job turnover rates are low in manufacturing and high in construction. Other demographic changes: There are more women and more Hispanic workers as a share of the US workforce. Male and Hispanic workers have higher job-to-job transition rates.

Job lock: The US has largely employer-sponsored health care, and employees may fear losing their health care if they switch jobs.

House lock: Workers who have low or negative home equity may find it difficult to move.

Contracting out: Workers who previously might have switched between short-duration jobs may now work for staffing firms or as independent contractors.

Unions: Union representation gives workers additional recourse during firing or layoff decisions Job search costs: Workers and employers may have more difficulty finding each other. Better matches: Workers may be better matched now than in previous decades and therefore obtain less benefit from switching.

Uncertainty: Firms may fear investing, and workers may fear losing their jobs.
Explains $9-21 \%$ of the decline [1].

Explains about $8 \%$ of the decline [1].

Explains about 3\% of the decline [1].

Explains $0-3 \%$ of the decline [1].

Consistent with the results of the multiworker job-search-and-matching model developed in [8].

May play a role, although studies on employment or revenue volatility and exporting find mixed evidence.

When local labor market conditions are worse, fewer workers switch jobs [9], a finding that is consistent with the predictions of labor market models where workers search while employed; see [10].

On net, there is a tiny offsetting positive effect (explains $-1 \%$ of the decline) because there are fewer stable manufacturing jobs [1].

Negligible effects [1].

Any effect of recent legislative changes regarding health insurance is likely to be offsetting.

Consistent only with the decline during the 20082009 recession; house prices continued to rise through the 2001 recession.

The increase in the employment share of the temporary help industry began during the 1990s, so it precedes these declines.

Private sector union employment continued to decline during the 2000s.

Does not seem to be consistent with the low cost of posting jobs and resumes on the internet.

Not consistent with the job search model in [10]; labor market downturns of 2001 and 2008-2009 should generate worse matches.

Explains the cyclicality, but does not seem to explain the lack of an increase in rates from 2001 to 2007.

Sources: Hyatt, H., and J. Spletzer. "The recent decline in employment dynamics." IZA Journal of Labor Economics 2:5 (2013): 1-21 [1]; Cairo, I. "The slowdown in business employment dynamics: The role of changing skill demands." Paper presented at the 2014 Society of Labor Economists Conference in Arlington, VA. Online at: https://sites.google.com/site/isabelcairo/Cairo_JMP.pdf [8]; Davis, S., and J. Haltiwanger. Labor Market Fluidity and Economic Performance. Prepared for the Federal Reserve Bank of Kansas City's symposium in Jackson Hole, WY. August 21-23, 2014. Online at: http://www.kc.frb.org/publicat/sympos/2014/083014-1.pdf [9]; Lise, J., C. Meghir, and J. M. Robin. Mismatch, Sorting, and Wage Dynamics. NBER Working Paper No. 18719, 2013 [10]. 
employment at young firms, which are more likely to be entrepreneurial and which have the highest rate of job turnover, explains about $8 \%$ of the decline. The shift in the distribution of educational attainment across the population toward more educated workers explains another $0-3 \%$ of the decline because turnover is lower among more educated workers. Industry composition has an offsetting effect on employment dynamics: the biggest change is the decline in manufacturing jobs, which tend to be stable. Thus, the decline in manufacturing, if anything, raised the rate of job-to-job flows.

The study also includes an extended exploration of other reasons why employment dynamics may have declined in recent years [1]. Expanding globalization may have played a role, as the US relied increasingly on imports during the 1990s, and China and other middle-income countries accounted for a rising share of global manufacturing output. Before the 1990s, the US might have responded more to shifts in global demand for goods and services, which would have triggered job-to-job flows.

Other studies offer additional insights into some of these proposed explanations, but the evidence is less direct. One study argues that the rise in high-skill jobs as a share of employment has made it more costly for employers to train workers and finds this change consistent with the predictions of a labor market job-search-and-matching model [8]. Another study relates employment reallocation rates (hires and job separations) to deteriorating local labor market conditions [9]. Similarly, recent estimates of labor market models that include workers searching while employed find that the decline in job-to-job transitions during the labor market downturns accompanying recessions reflects a decline in available opportunities for workers [10]. This prediction is consistent with evidence on a decline in the benefits of changing jobs between the 1980s and more recent years [3]. Another argument is that labor market job matching worsens during labor market downturns, so during recessions workers enter jobs that are worse than the ones they would enter in better economic conditions [10]. The fact that the recent large declines in the job-to-job flow rate occurred during labor market downturns associated with recessions suggests that the quality of current job matches should be lower, not higher, than that during the late 1990s. This implies that the slowdown in the job-to-job flow rate was not due to workers having entered into better matches.

\section{LIMITATIONS AND GAPS}

Despite the many potential explanations that have been proposed for the decline in job-to-job flow rates, definitive evidence is lacking on why the flow rate has fallen to such unprecedentedly low levels. One reason for the lack of evidence is that there are naturally no observations for potential matches that do not occur. This is a problem that macroeconomists have dealt with for decades, but the typical solution involves invoking a complex model. Complex models generally require assumptions with a great deal of specificity, and inferences are only as good as the models on which they are based. Therefore, even the most detailed understanding of the causes and consequences of the decline in job-to-job flows will necessarily involve a great deal of uncertainty.

The study of job-to-job transitions is still quite new, and there are a variety of open questions:

- Most analyses of the decline in job-to-job flow rates, as well as in employment dynamics more broadly, have been descriptive, and economic modeling to understand these dramatic declines has only begun recently. 
- Labor market composition changes, such as the aging of the workforce, rising educational attainment, and declining entrepreneurship, explain a small amount of the decline in the job-to-job flow rate, but the main causes are unknown.

- There are no comprehensive data sets on employer hiring costs and training costs.

- The benefits of job-to-job flows are difficult to quantify, and drawing inferences about these benefits generally involves a structural macroeconomic model that involves assumptions that are difficult to test. For example, there is no way to conduct a randomized controlled trial to distinguish the effects of high and low unemployment rates on a labor market.

- There are gaps in the US data on job-to-job flow rates in the 1950s and 1960s, although historical data on job tenure may help to fill in the gaps.

- It is difficult to know whether the trends in the US are part of a broader phenomenon among advanced economies because of the lack of data on job-to-job flows for other economies.

\section{SUMMARY AND POLICY ADVICE}

Whether a decline in the job-to-job flow rate, as has happened in the US, is good or bad depends on which of several potential explanations is the true underlying cause of the decline. If workers are better matched now than they were in the 1990s, then the previously higher rates of job-to-job flows may have simply reflected the reallocation of workers in response to longer-term structural changes, a process that has now largely run its course.

Job-to-job transitions also have natural costs and benefits, and the costs are easier to identify. For workers, there are relocation costs, job lock-in related to employer-provided health care, and educational costs associated with acquiring qualifications for a different occupation. For employers, there are the costs of laying off or firing workers, of recruiting appropriate workers to fill their jobs, and of training new workers. The benefits of job-tojob flows are more amorphous and can in general only be inferred indirectly. A constant job-to-job flow rate requires a steady stream of jobs that are more productive than the ones that exist at a particular point in time, allowing employers to offer wages that induce workers to change jobs.

\section{Acknowledgments}

The author thanks an anonymous referee and the IZA World of Labor editors for many helpful suggestions on earlier drafts. Previous work of the author contains a larger number of background references for the material presented here and has been used intensively in all major parts of this article [1], [2], [7]. Any opinions and conclusions expressed herein are those of the author and do not necessarily represent the views of the US Census Bureau. All results have been reviewed to ensure that no confidential data are disclosed.

\section{Competing interests}

The IZA World of Labor project is committed to the IZA Guiding Principles of Research Integrity. The author declares to have observed these principles. 


\section{REFERENCES}

\section{Further reading}

Hyatt, H., and E. McEntarfer. "Job-to-job flows in the Great Recession." American Economic Review: Papers and Proceedings 102:3 (2012): 580-583.

Hyatt, H., and J. Spletzer. "Hires, separations, and the job tenure distribution in administrative earnings records." In: JSM Proceedings, Business and Economic Statistics Section. Alexandria, VA: American Statistical Association, 2014; pp. 231-245.

\section{Key references}

[1] Hyatt, H., and J. Spletzer. "The recent decline in employment dynamics." IZA Journal of Labor Economics 2:5 (2013): 1-21.

[2] Hyatt, H., and E. McEntarfer. Job-to-Job Flows and the Business Cycle. US Census Bureau Center for Economic Studies Working Paper No. 12-04, 2012. Online at: ftp://ftp2.census.gov/ces/ wp/2012/CES-WP-12-04.pdf

[3] Molloy, R., C. Smith, and A. Wozniak. Declining Migration Within the U.S.: The Role of the Labor Market. NBER Working Paper No. 20065, 2014.

[4] Farber, H. "Mobility and stability: The dynamics of job change in labor markets." In: Ashenfelter, O., and D. Card (eds). Handbook of Labor Economics Volume 3. Amsterdam: North Holland, 1999; pp. 2439-2483.

[5] Stewart, J. "Using March CPS data to analyze labor market transitions." Journal of Economic and Social Measurement 32:2-3 (2007): 177-197.

[6] Fallick, B., and C. Fleischman. Employer-to-Employer Flows in the U.S. Labor Market: The Complete Picture of Gross Worker Flows. Board of Governors of the Federal Reserve System, Finance and Economics Discussion Series No. 2004-34, 2004. Online at: http://www.federalreserve.gov/ pubs/feds/2004/200434/200434pap.pdf

[7] Hyatt, H., E. McEntarfer, K. McKinney, S. Tibbets, and D. Walton. "Job-to-job (J2J) flows: New labor market statistics from linked employer-employee data." In: JSM Proceedings, Business and Economic Statistics Section. Alexandria, VA: American Statistical Association, 2014; pp. 98-110.

[8] Cairo, I. "The slowdown in business employment dynamics: The role of changing skill demands." Paper presented at the 2014 Society of Labor Economists Conference in Arlington, VA. Online at: https://sites.google.com/site/isabelcairo/Cairo_JMP.pdf

[9] Davis, S., and J. Haltiwanger. Labor Market Fluidity and Economic Performance. Prepared for the Federal Reserve Bank of Kansas City's symposium in Jackson Hole, WY. August 21-23, 2014. Online at: http://www.kc.frb.org/publicat/sympos/2014/083014-1.pdf

[10] Lise, J., C. Meghir, and J. M. Robin. Mismatch, Sorting, and Wage Dynamics. NBER Working Paper No. 18719, 2013.

The full reference list for this article is available from the IZA World of Labor website (http://wol.iza.org/articles/decline-in-job-to-job-flows). 